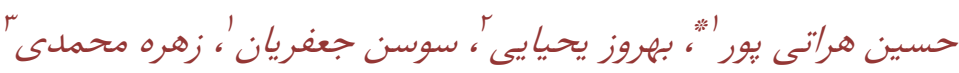

'استاديار كودكان، كروه يزشكى، واحد شاهرود، دانشخاه آزاد اسلامى، شاهرود، ايران

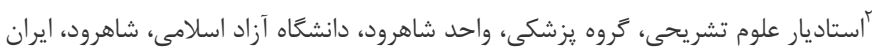

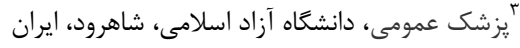

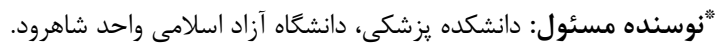

يست الكترونيك: hharatipour@yahoo.com

حكبر

زمينه و هدف: سيسيس نوزادى مهمترين بيمارى T1 روز اول زندكى /ست كه تشخيص قطعى وجود آن

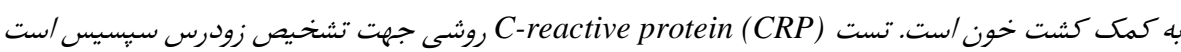

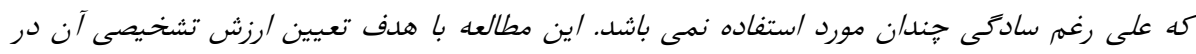

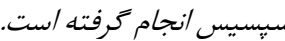

مواد و روش كار:/ين مطالعه مقطعى بوده و بر روى نوز/دان بيمارستانهاى شاهرود انجام كرفته /ست.

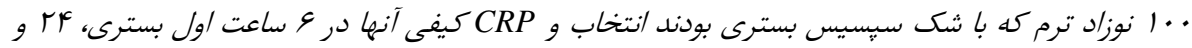

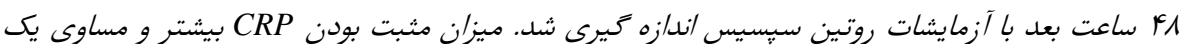
مثبت در نظر كرفته شد.

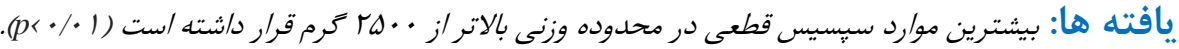
راع٪ نوزادان مورد بررسى ترم بوده كه در بين آنها و/VN٪ مبتلا به سبسيس قطعى بودند كه تفاوت معنى

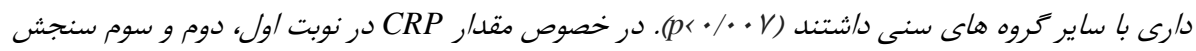

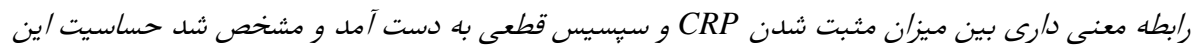

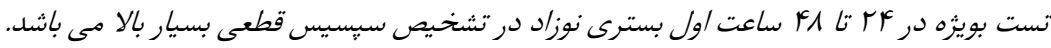
نتيجه تَيرى: /ين يزوهش نشان داد كه سطح سرمى CRP مى تواند به عنوان يك تست سريع بويزه در

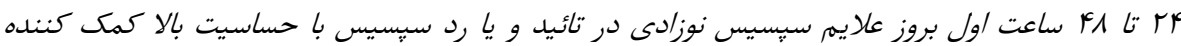

وازه هاى كليلى: بروتئين واكنشى سى، سبِيس نوزادى، سرم خون

وصول:qr/lr/r

94/9/9: اصلاح:

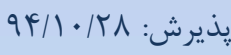

DOI: $10.18869 /$ acadpub.jnkums.8.2.363

Cite this article as: Haratipour H, Yahyaei B, Jafarian S, Mohammadi Z. Validity of the CRP diagnostic test in identifying the neonates with sepsis. jnkums. 2016; 8 (2) $: 363-372$ 
جون آميى سيلين و جنتامايسين مى باشد كه مصرف

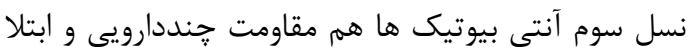

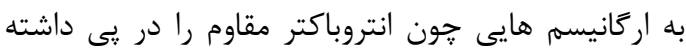

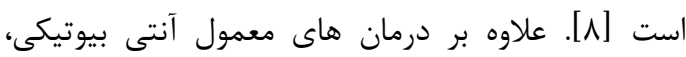
توجه به وضعيت آب و الكتروليت و هموديناميك بيمار و و داني

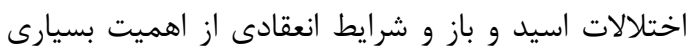
برخوردار مى باشد [9]. شروع درمان آنتى بيوتيكى علاوه بر اينكه اثرات جانتي آنتى

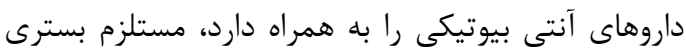

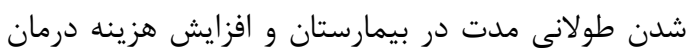

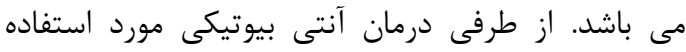

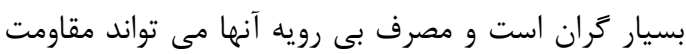

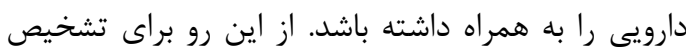
سريع تر سيسيس نوزادى، تستى مورد نياز است كه

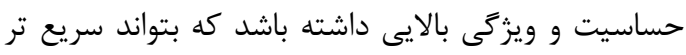

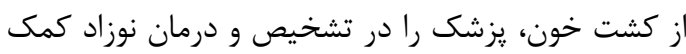

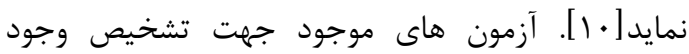
التهاب شامل CRP، هايتو ملوبين، فيبرينوزن و هوجون هايتوكين

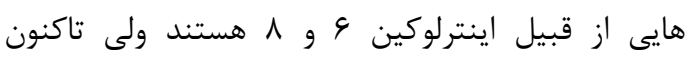
مشخص نشده است كه كدام يك از ماركرهاى فوق إن

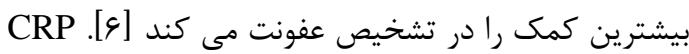

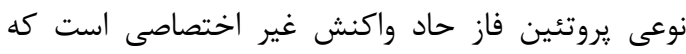

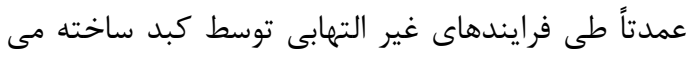

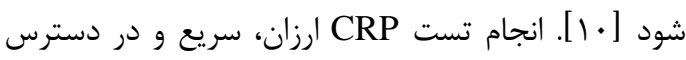

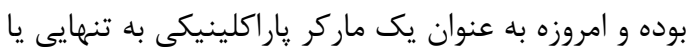
در تركيب با ساير فاكتورهاى ياراكلينيكى جهت باريك آغاز درمان تجربى سيسيس نوزادى مورد بحث بوده است باتي

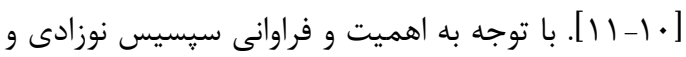

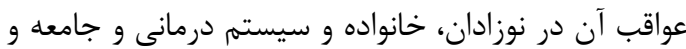

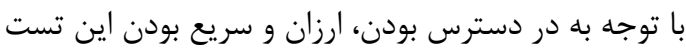

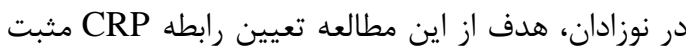

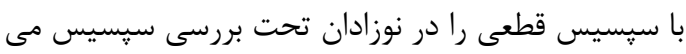

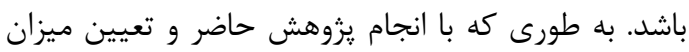

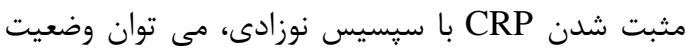

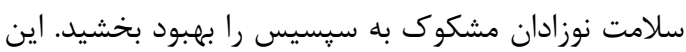
مسأله بخصوص در مورد نوزادانى كه بيقرار بوده، بى اشتها و بى حال هستند و كاهش رفلكس هاى نوزادى و علائم بيمارى هاى عفونى در دوره نوزادى خصوصا سيسيس

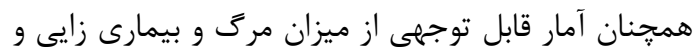

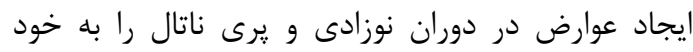

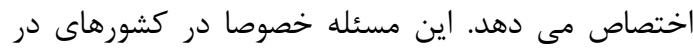

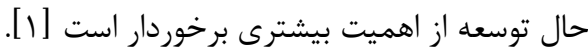

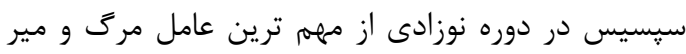
به خصوص در كشورهاى در حال توسعه و در بين نوزادان نارس و كم وزن به شمار مى رود. به علاوه اين نوزادان به به به دران

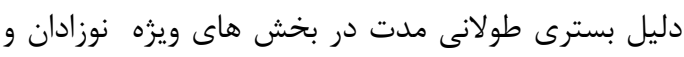

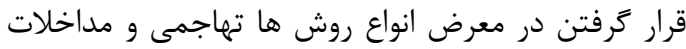
مختلف در خطر انواع عفونت هاى با اركانيسم هاى مقاوم

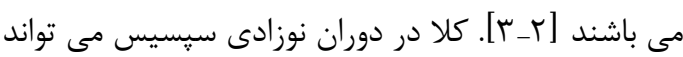

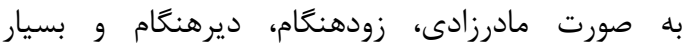

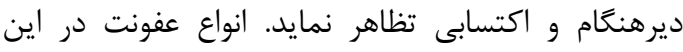

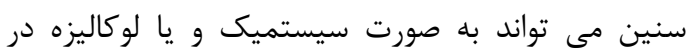
منطقه و يا اركان خاصى بروز كند [ب]. تظاهرات سيسيس نوزادى مى تواند بسيار مبهم و غيراختصاصى باشد كاند كه

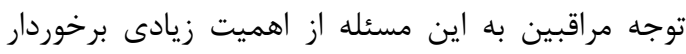

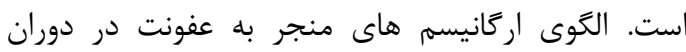

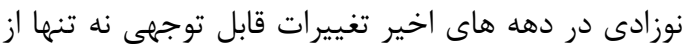

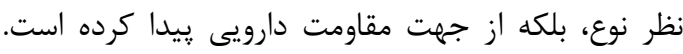

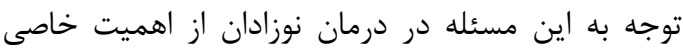
برخوردار مى باشد [ه]. تشخيص سيسيس نوزادى با انجام كشت خون قطعى شده

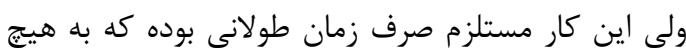
عنوان به نفع نوزاد نمى باشد لذا لازم است از إن تست هايى إنى

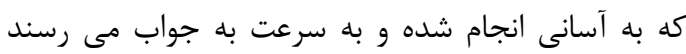
استفاده شود كه در اين خصوص مى توان به CRP اشاره

كرد [ع]

استفاده گسترده و بى رويه از آنتى بيوتيك هاى نسل سوم

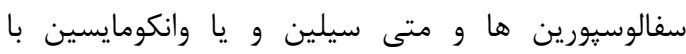
مقاومت دارويى قابل توجهى نه تنها در عفونت هاى بيمارستانى بلكه در عفونت هاى اكتسابى محيطى در دابل دوره

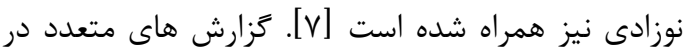
دهاه هاى اخير و حتى از سوى سازمان جهانى بهداشت أندان

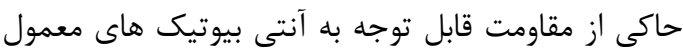




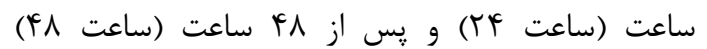

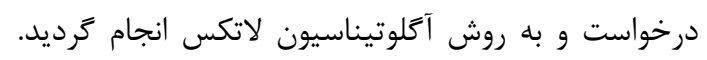

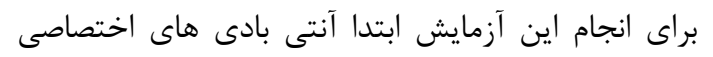
ضد CRP را با تزريق CRP به حيوانات آزمايشكاهى تهيد آنسيه

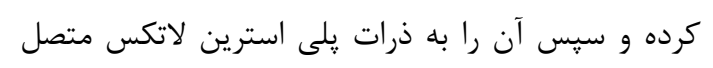

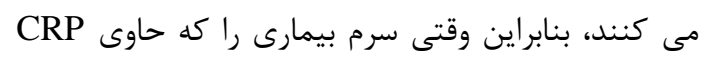
است با ذرات فوق مخلوط شود، باعث ايجاد آكلوتيناسيون

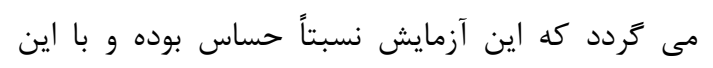
روش ميتوان بر حسب موسسه سازنده در يك آنس ميلى ليتر

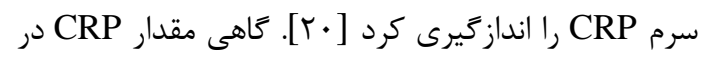

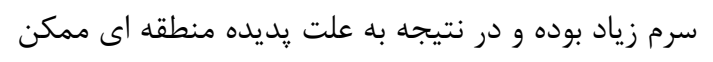

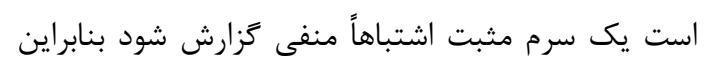

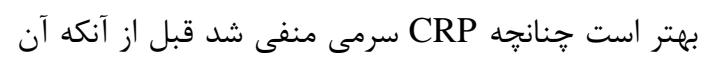

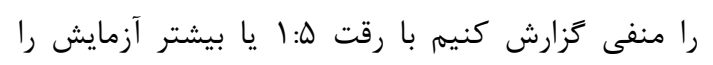

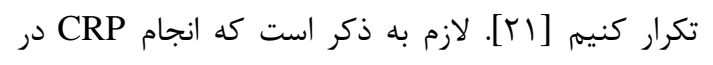

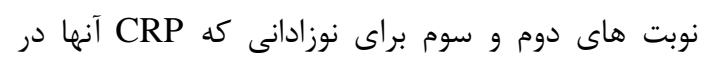

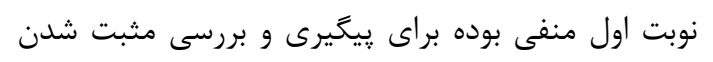

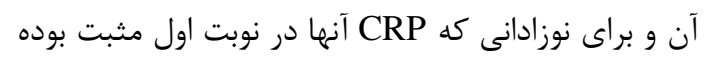

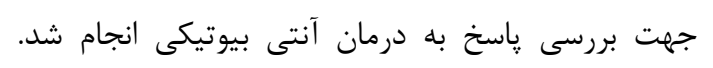

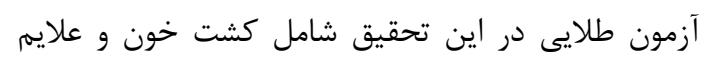

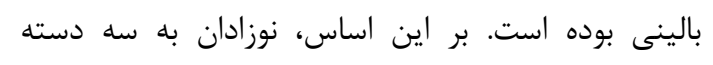
سيسيس قطعى (كشت خون مثبت)، سيسيس محتمل

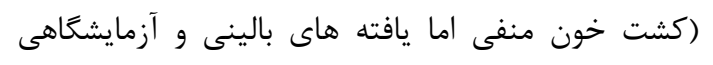

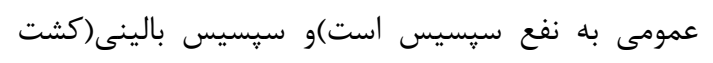

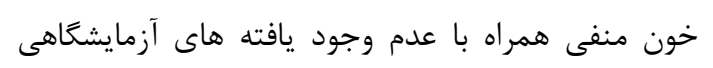

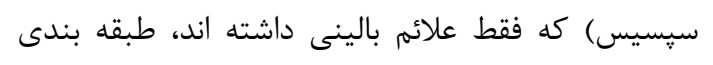

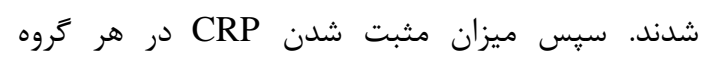
مشخص و با هم مقايسه شد. نتايج معاينات و آزمايشات

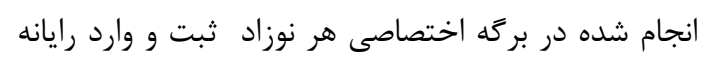

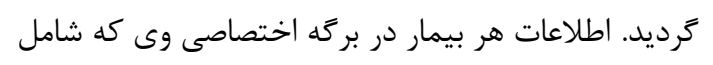

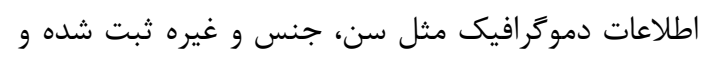

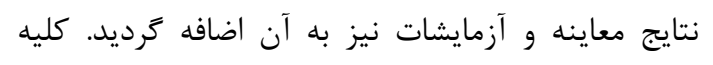

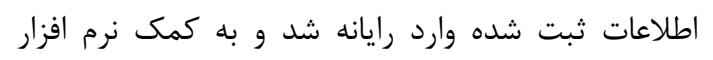
آمارى SPS16، مورد تجزيه و و تحليل قراركرفت. آمار

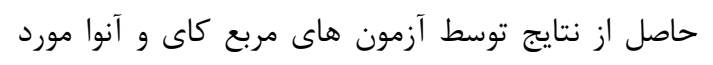

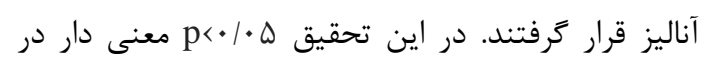
نظر كرفته شد.
غير اختصاصى ديخر و غيره دارند، بسيار مههم و حياتى

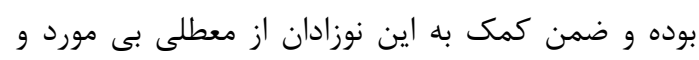

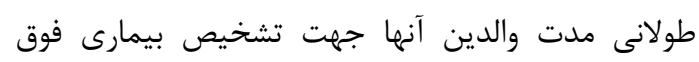

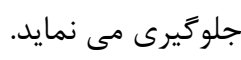

\section{روش كار}

اين مطالعه، به صورت يك مطالعه ى توصيفى- مقطعى

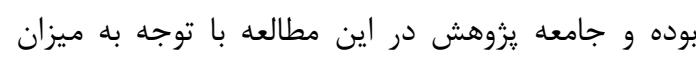

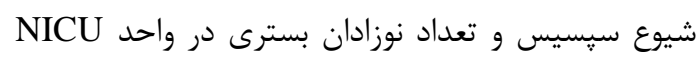

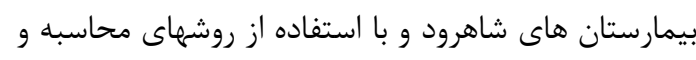

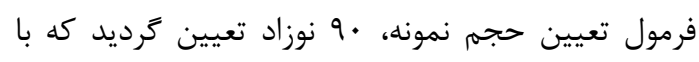

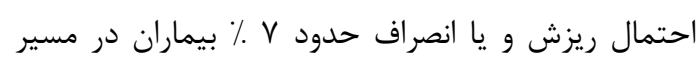

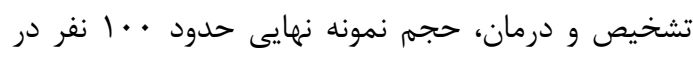

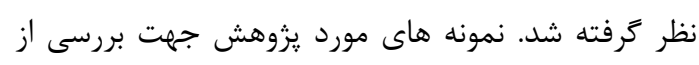

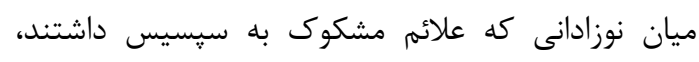

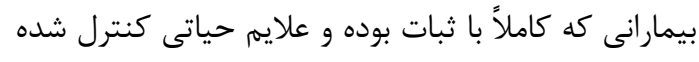

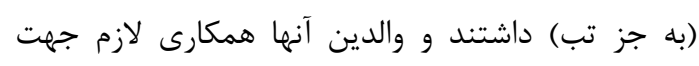

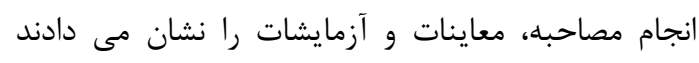

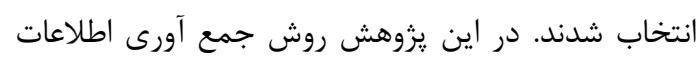

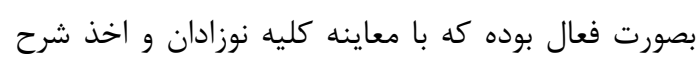

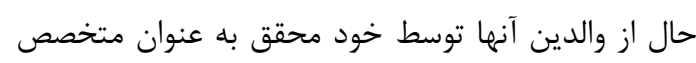
اطفال انجام كرفت. معيارهاى ورود نوزادان در مطالعه حاضر، دارا بودن يك يا קند ريسك فاكتور مادرى سيسيس نوزادى از قبيل سابقه

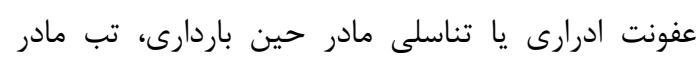

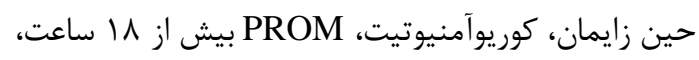

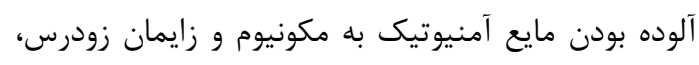

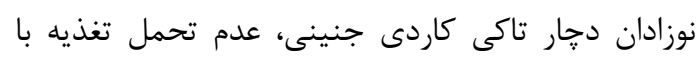

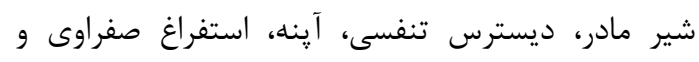

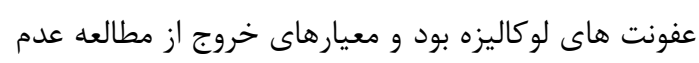
رضايت والدين جهت شركت در طرح بوده است. براى كليه

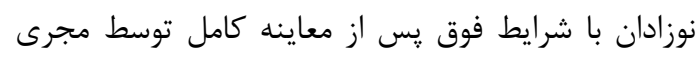

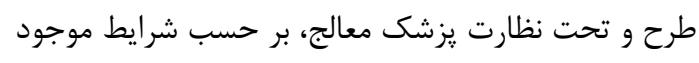

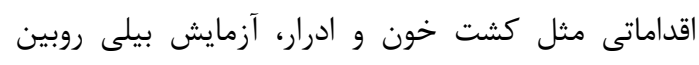

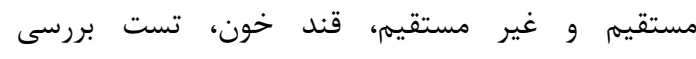

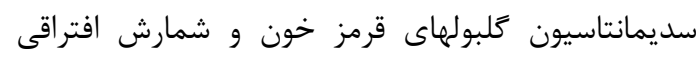

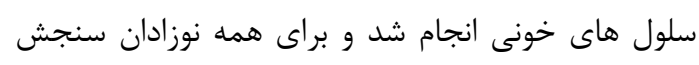

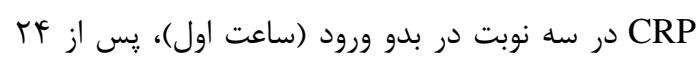


جنين، اع/٪ نوزادان مورد بررسى ترم بوده كه در بين آنها VN/9 مبتلا به سيسيس قطعى بودند كه تفاوت معنى

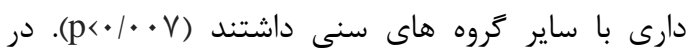

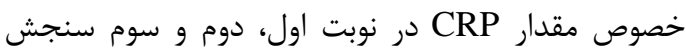
رابطه معنى دارى بين ميزان مثبت شدن CRP و

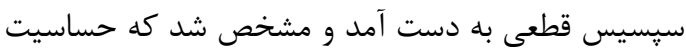

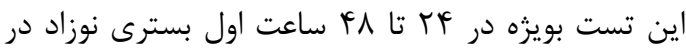

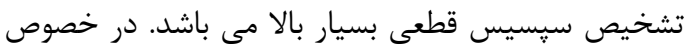

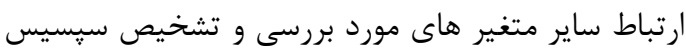
نيز ارتباط معنى دارى به دست نيامد.

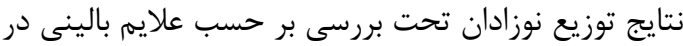
جداول I ارائه شده است. در اين مطالعه مقادير كيفى

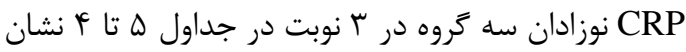

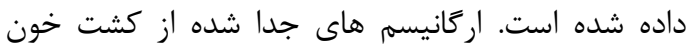

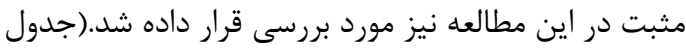

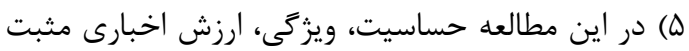

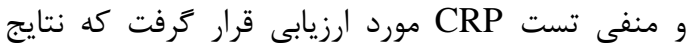
حاصل از آن در جدول 9 نشان داده شده است.

اين اطلاعات شامل خصوصيات . ․

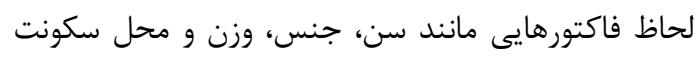

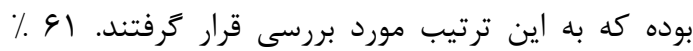

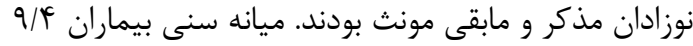

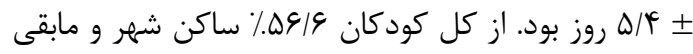

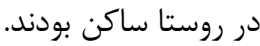
ميانه وزنى نوزادان كه در سيسيس قطعى، ميانه وزنى به طور معنى دارئ دارى

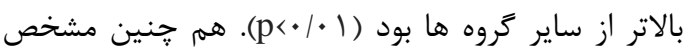
كرديد كه بيشترين موارد سيسيس قطعى در در محدوده

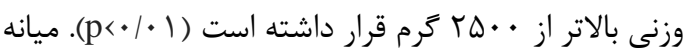

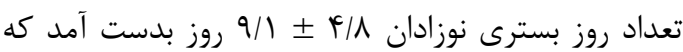
در سيسيس قطعى به طور معنى دارى كمتر از ساير گروه

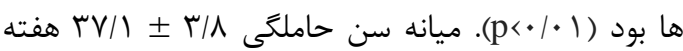

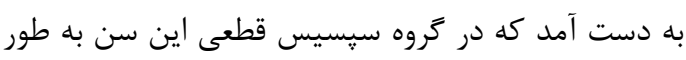
معنى دارى نزديك تر به سن حاملكى طبيعى بود

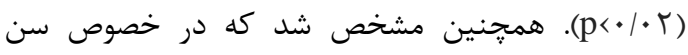

\begin{tabular}{|c|c|c|c|c|c|}
\hline p-value & تمع بالينى & 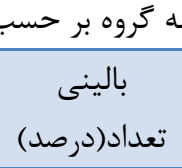 & ادان تحت براد(درصد & إ: توزيع فراوانى & علائم بالينى \\
\hline \multirow[t]{7}{*}{$\mathrm{p}<\cdot / \cdot \cdot \vee$} & $\left(Y^{F}\right) Y^{F}$ & $(\mid r / \Delta) \mid$ & $(r \varepsilon / 9) r_{1}$ & \multirow{2}{*}{$\begin{array}{l}(\mid F) Y \\
(Y N / q) Y\end{array}$} & خوب شير نخوردن \\
\hline & $(19) 19$ & $(\mid K / \Delta) \mid$ & $(\mid F / \Lambda) \|$ & & نايايدارى درجه حرارت \\
\hline & $(\mid F) \mid F$ & $(\mid r / \Delta) \mid$ & $(\mid f / \Lambda) \|$ & $(I F / T) Y$ & بى قرارى \\
\hline & $(r \Delta) r \Delta$ & $(\mid r / \Delta) \mid$ & $(r V / r) r q$ & $(r \Delta / V) \Delta$ & لت لتارزى \\
\hline & $(q V) \& V$ & $(r V / Q) r$ & $(\mathcal{F} V / \mathcal{F}) \Psi V$ & $(\Delta \cdot) V$ & ديسترس تنفسى \\
\hline & $(Y \cdot) Y \cdot$ & $(T V / Q) r$ & $(19 / \%) 10$ & $(\mid F / T) Y$ & زردى \\
\hline & $(1 \cdot) 1 \cdot$ & $(\mid r / \Delta) \mid$ & $(V \vee)^{q}$ & $(r \mid / Y) r$ & استفراغ \\
\hline
\end{tabular}

جدول ז: توزيع فراوانى نوزادان تحت بررسى سه كروه بر حسب CRP نوبت اول

\begin{tabular}{|c|c|c|c|c|c|c|}
\hline p-value & تعداد(درصد كل & تعداد(درصد) & تعداد(درصد) احتمالى & تعداد(درصد) & نوع سيسيس & CRP \\
\hline \multirow[t]{3}{*}{$\mathrm{p}<\cdot / \cdot r$} & $(1 \cdot) 1$. & \multirow{2}{*}{$\begin{array}{c}- \\
(1 \cdot \cdots) \wedge\end{array}$} & $(1 / \Gamma) 1$ & \multirow{2}{*}{$\begin{array}{l}(\Phi \varphi / \Psi) q \\
(r \Delta / V) \Delta\end{array}$} & Positive & \\
\hline & (9.) 9 . & & $(q \wedge / \vee) \vee V$ & & Negative & \\
\hline & $(1 \cdots)) \ldots$ & $(1 \cdots) \wedge$ & $(1 \cdots) \vee \wedge$ & $(1 \cdot \cdots) \mid f$ & جمع كل & \\
\hline
\end{tabular}




\begin{tabular}{|c|c|c|c|c|c|c|}
\hline \multicolumn{7}{|c|}{ جدول ऍّ: توزيع فراوانى نوزادان تحت بررسى سه گروه بر حسب CRP نوبت دوم } \\
\hline p-value & تعداد(درصد كل & تعداد(درصد) & تعداد(درصد) احتمالى & تعداد(درصد) قطى & 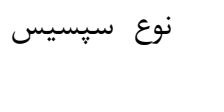 & CRP \\
\hline \multirow[t]{3}{*}{$\mathrm{p}<\cdot / \cdot 1$} & $(1 \Delta) 10$ & \multirow{2}{*}{$\begin{array}{c}- \\
(1 \cdot \cdots) \wedge\end{array}$} & $(r / 9) r$ & \multirow{2}{*}{$\begin{array}{l}(9 r / 9) \mid r \\
(V / 1) 1\end{array}$} & \multirow{2}{*}{\multicolumn{2}{|c|}{$\begin{array}{l}\text { Positive } \\
\text { Negative }\end{array}$}} \\
\hline & $(\wedge \Delta) \wedge \Delta$ & & $(9 \vee / 4) \vee G$ & & & \\
\hline & $(1 \cdots) 1 \cdots$ & $(1 \cdots) \wedge$ & $(1 \cdots) \vee \wedge$ & $(1 \cdots) \mid f$ & \multicolumn{2}{|l|}{ جمع كل } \\
\hline
\end{tabular}

\begin{tabular}{|c|c|c|c|c|c|c|}
\hline \multicolumn{7}{|c|}{ جدول fا: توزيع فراوانى نوزادان تحت بررسى سه گروه بر حسب CRP نوبت سوم } \\
\hline p-value & تعداد(درصد كل) & تعداد(درصد) بالينى & تعداد(درصد) احتمالى & تعداد(درصد) قطعى & 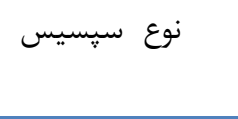 & CRP \\
\hline \multirow[t]{3}{*}{$\mathrm{p}<\cdot / \cdot r$} & $(\mid f) \mid f$ & \multirow{2}{*}{$\begin{array}{c}- \\
(1 \cdots) \wedge\end{array}$} & - & \multirow{2}{*}{$\begin{array}{c}(1 \cdots) \mid f \\
-\end{array}$} & \multicolumn{2}{|l|}{ Positive } \\
\hline & $(\wedge \varphi) \wedge \varepsilon$ & & $(1 \cdots) \vee \wedge$ & & \multicolumn{2}{|c|}{ Negative } \\
\hline & $(1 \cdots) 1 \cdots$ & $(1 \cdots) \wedge$ & $(1 \cdots) \vee \wedge$ & $(1 \cdots) \mid f$ & جمع كل & \\
\hline
\end{tabular}

\begin{tabular}{|c|c|}
\hline تعداد(درصد) & اركانيسم جدا شده از كشت خون \\
\hline$F(Y \wedge / V \Delta)$ & E-coli \\
\hline$r(r \mid / F T)$ & Klebseilla \\
\hline$I(V / I Y)$ & Staphylococcus coagulase + \\
\hline$r(\mid F / T \wedge)$ & Staphylococcus coagulase - \\
\hline$r(\mid F / Y \wedge)$ & Citrabacter \\
\hline$l(V / I F)$ & Gram negative Basiluse \\
\hline$I(V / I F)$ & Salmonella \\
\hline $\mid f(\mid \cdot)$ & جمع كل(درصد) \\
\hline
\end{tabular}




\begin{tabular}{|c|c|c|c|c|}
\hline \multicolumn{5}{|c|}{ جدول 9: توزيع فراوانى نوزادان تحت بررسى بر حسب آزمون هاى بررسى CRP } \\
\hline $\begin{array}{c}\text { ارزش اخبارى منفى (درصد) } \\
\text { (درى }\end{array}$ & ارزش اخبارى مثبت & ويزگى (درصد) & حساسيت & $\begin{array}{l}\text { زمان سنجش CRP آزمون ها } \\
\text { آل }\end{array}$ \\
\hline qr & Tr & $9 V$ & sq & ساعت اول \\
\hline $99 / 4$ & II/V & $9 \Lambda / \mu$ & $9 r / 9$ & ساعت TF \\
\hline $1 \cdots$ & $\Gamma \Delta / \mu$ & $\Lambda \omega / \omega$ & $1 \ldots$ & ساعت Y \\
\hline
\end{tabular}

نشان داد كه با كذشت زمان قدرت تشخيصى

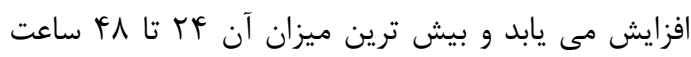

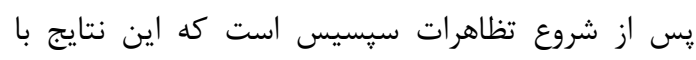

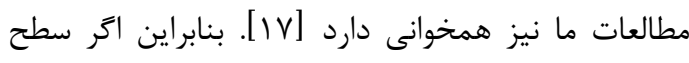

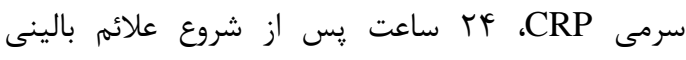

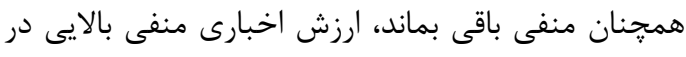

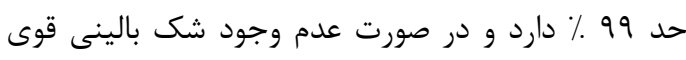

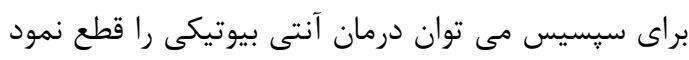

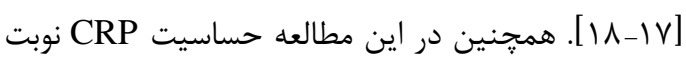

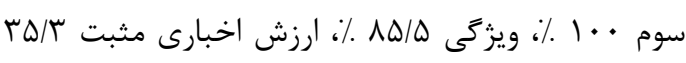

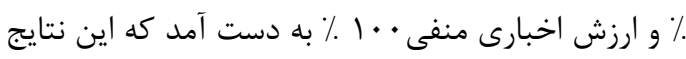

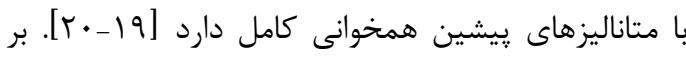

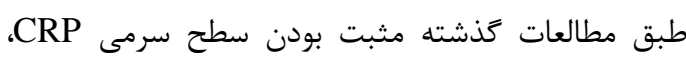

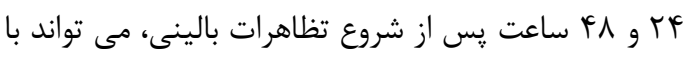

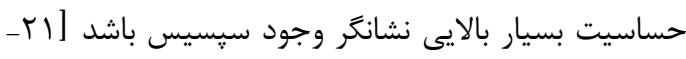

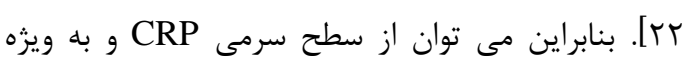

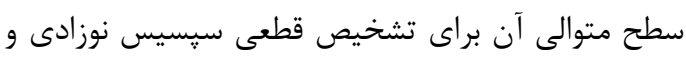

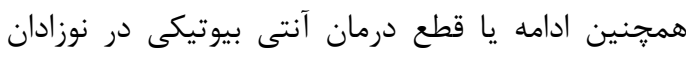

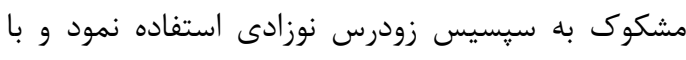

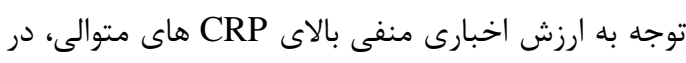

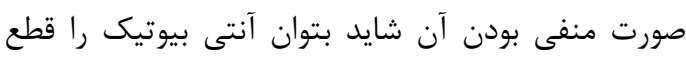

\section{نتيجه كيرى تمون}

استنتاج كلى اين يزوهش حاكى از آن است كه سطح سرمى CRP مى تواند به عنوان يك تست ساده، ارزان و أن است كه سطح
در اين مطالعه ويزگى و ارزش اخبارى منفى CRP نوبت

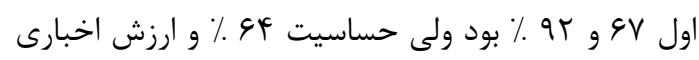

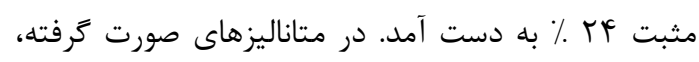

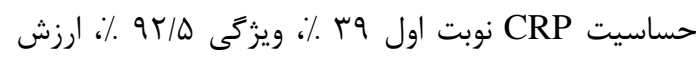

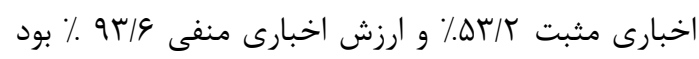

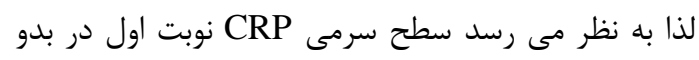

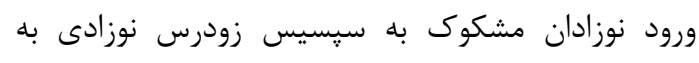

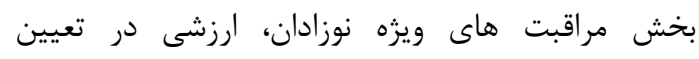

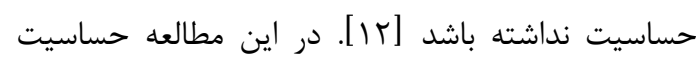

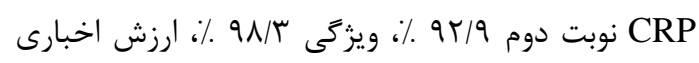

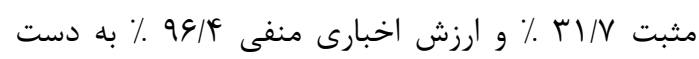

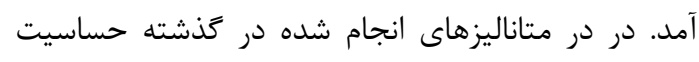

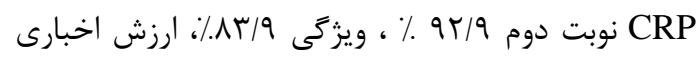

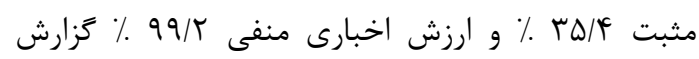

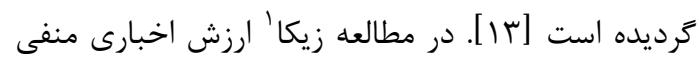

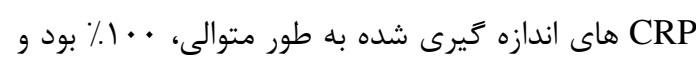

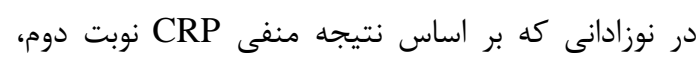

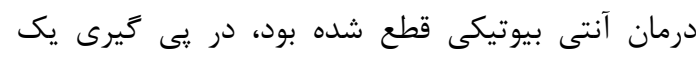

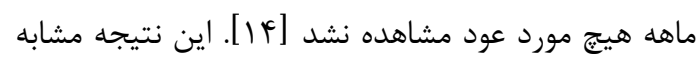

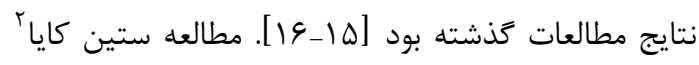

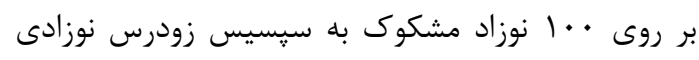

1 - Zecca

2 - Cetinkaya 


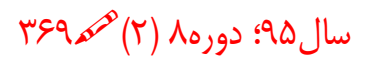

داده و نتايج آن ها را بررسى نمود. همجنين با توجه به

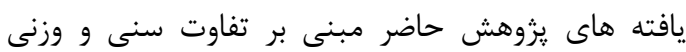

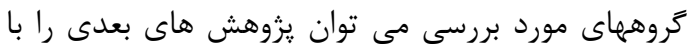

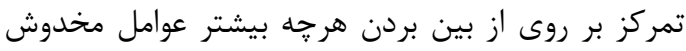

كر و توليد نتايج دقيق تر انجام داد.

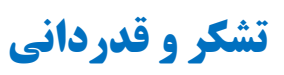

بدين وسيله نويسندكان مقاله از حمايت هاى مسئولين

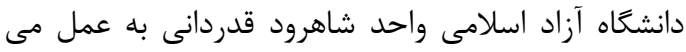

آورند.
مجله دانشگاه علوم يزشكى خراسان شمالى

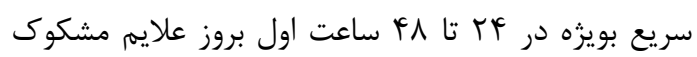

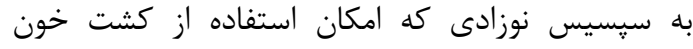

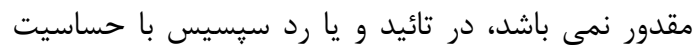

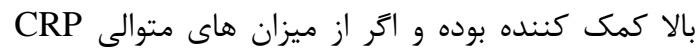

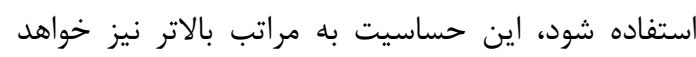

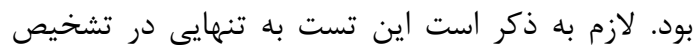

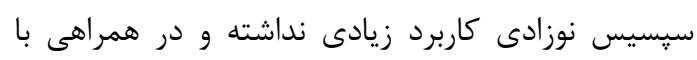
ساير تست هاى آزمايشكاهى ارزش تشخيصى بالايى يِيدا

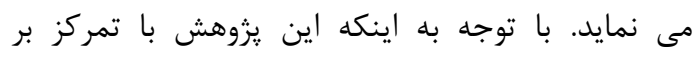

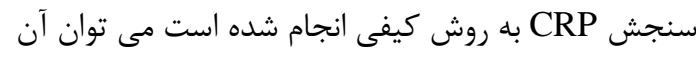
را جهت دقت بيشتر با كيت هاى CRP كمى نيز انجام 


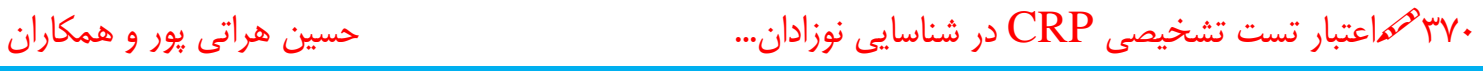

\section{References}

1. Prashant A, Vishwanath P, Kulkarni P, Sathya Narayana P, Gowdara V, "et al", Comparative assessment of cytokines and other inflammatory markers for the early diagnosis of neonatal sepsis-a case control study, PLoS One, 2013: 8(7), e68426.

2. Boonkasidecha S, Panburana J, Chansakulporn S, Benjasuwantep B, Kongsomboon K, An optimal cut-off point of serum C-reactive protein in prediction of neonatal sepsis, J Med Assoc Thai, 2013: 1, S65-70.

3. Adib M, Bakhshiani Z, Navaei F, Saheb Fosoul F, Fouladi S, “ et al", Procalcitonin: a reliable marker for the diagnosis of neonatal sepsis, Iran J Basic Med Sci, 2012: 15(2), 777-82.

4. O'Shea TM, Shah B, Allred EN, Fichorova RN, Kuban KC, "et al", Inflammation-initiating illnesses, inflammation-related proteins, and cognitive impairment in extremely preterm infants, Brain Behav Immun, 2013: 29, 104-12.

5. Bustos B R, Araneda C H,Procalcitonin for the diagnosis of late onset sepsis in newborns of very low birth weight,Rev Chilena Infectol, 2012: 29(5), 511-6.

6. Gokmen Z, Ozkiraz S, Kulaksizoglu S, Kilicdag H, Ozel D, “ et al”, Resistin-a novel feature in the diagnosis of sepsis in premature neonates,Am J Perinatol, 2013: 30(6), 513-8.

7. Coghe F, Orrù G, Ferraguti P, Accossu S, Faa R, "et al", C-reactive protein levels in the first days of life: a systematic statistical approach,J Matern Fetal Neonatal Med, 2012: 25(5), 47-50.

8. West BA, Peterside O, Ugwu RO, Eneh AU, Prospective evaluation of the usefulness of C-reactive protein in the diagnosis of neonatal sepsis in a sub-Saharan African region, Antimicrob Resist Infect Control 2012: 1, 1(1):22.

9. Lee SY, Park KH, Jeong EH, Oh KJ, Ryu A, Park KU, Relationship between maternal serum Creactive protein, funisitis and early-onset neonatal sepsis,J Korean Med Sci, 2012: 27(6), 674-80.

10.Mondal SK, Nag DR, Bandyopadhyay R, Chakraborty D, Sinha SK, Neonatal sepsis: Role of a battery of immunohematological tests in early diagnosis,Int J Appl Basic Med Res, 2012: 2(1), 43-7.

11.Payne MS, Goss KC, Connett GJ, Legg JP, Bruce KD, "et al", A quantitative analysis of Ureaplasma urealyticum and Ureaplasma parvum compared with host immune response in preterm neonates at risk of developing bronchopulmonary dysplasia, J Clin Microbiol, 2012: 50(3), 909-14.

12.Waliullah SM, Islam MN, Siddika M, Hossain MA, Jahan I, "et al", Evaluation of simple hematological screen for early diagnosis of neonatal sepsis,Mymensingh Med J, 2010: 19(1), 41-7.

13.Shin SH, Choi CW, Lee JA, Kim EK, Choi EH, "et al",Risk factors for serious bacterial infection in febrile young infants in a community referral hospital,J Korean Med Sci, 2009: 24(5), 844-8.

14.Zecca E, Barone G, Corsello M, Romagnoli C, Tiberi E, "et al",Reliability of two different bedside assays for C-reactive protein in newborn infants.Clin Chem Lab Med, 2009: 47(9), 1081-4.

15.Khassawneh M, Khader Y, Abuqtaish N, Clinical features of neonatal sepsis caused by resistant Gram-negative bacteria,Pediatr Int, 2009: 51(3), 332-6.

16.Reier-Nilsen T, Farstad T, Nakstad B, Lauvrak V, Steinbakk M, Comparison of broad range 16S rDNA PCR and conventional blood culture for diagnosis of sepsis in the newborn: a case control study,BMC Pediatr, 2009: 9(1), 5.

17.Cetinkaya M, Ozkan H, Köksal N, Celebi S, Hacimustafaoğlu M, Comparison of serum amyloid A concentrations with those of C-reactive protein and procalcitonin in diagnosis and follow-up of neonatal sepsis in premature infants, J Perinatol, 2009: 29(3), 225-31.

18.Sakha K, Husseini MB, Seyyedsadri N, The role of the procalcitonin in diagnosis of neonatal sepsis and correlation between procalcitonin and C-reactive protein in this patients.Pak J Biol Sci, 2008: 11(14), 1785-90[Persian]

19. Shaoul R, Lahad A, Tamir A, Lanir A, Srugo I, C reactive protein (CRP) as a predictor for true bacteremia in children, Med Sci Monit, 2008: 14(5), 255-261.

20.Schmidt N, Palma J, King A, Santolaya ME, C-reactive protein and procalcitonin levels for the diagnosis of invasive bacterial infections in allogenic hematopoietic stem cell transplantation recipients.Rev Med Chil, 2007: 135(8), 982-9. 


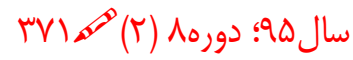

مجله دانشگاه علوم يزشكى خراسان شمالى

21.Chowdhary G, Dutta S, Narang A, Randomized controlled trial of 7-Day vs. 14-Day antibiotics for neonatal sepsis,J Trop Pediatr, 2006: 52(6), 427-32.

22. Jincharadze N, Abelashvili D, McHedlishvili M, Kacharava M, Diagnostic value of C-reactive protein test at early-onset sepsis in preterm infants, Georgian Med News, 2006: 130, 87-91. 


\title{
Validity of the CRP diagnostic test in identifying the neonates with sepsis
}

\author{
Haratipour $H^{1 *}$, Yahyaei $B^{2}$, Jafarian $S^{1}$, Mohammadi $Z^{3}$ \\ ${ }^{1}$ Assistant professor of Pediatrics, Departmentt of Medical Sciences, Shahrood Branch, \\ Islamic Azad University, Shahrood, Iran. \\ ${ }^{2}$ Assistant professor of Anatomical Sciences, Departmentt of Medical Sciences, Shahrood Branch, \\ Islamic Azad University, Shahrood, Iran. \\ ${ }^{3} \mathrm{MD}$, Shahrood Branch, Islamic Azad University, Shahrood, Iran \\ *Corresponding author: Shahrood Branch, Islamic Azad University, Shahrood, Iran. \\ Email: hharatipour@yahoo.com
}

\section{Abstract}

Background and Objective: Neonatal Sepsis is the most important disease in the first 28 days of life which is diagnosed definitely using the blood culture. The $C$-reactive protein test (CRP) is a simple method for the early diagnosis of sepsis, which is not so used. This study was conducted to determine the diagnostic value of this method in sepsis.

Materials and Methods: This cross-sectional study was performed on 100 newborns that were suspected of sepsis in Shahrood hospitals. Their quality CRP was measured using sepsis routine tests in the first 6, 24, and 48 hours of admission. The CRP $y$ was considered as positive CRP.

Results: Most of the certain sepsis cases were among the new borns who were heavier than $2500 \mathrm{~g}(p<0.01)$. The gestational mean age was $8.3 \pm 1.37$ weeks, in this age group definite sepsis was significantly closer to the normal gestational age ( $p<0.02)$. Sixty one percentage of cases were full-term infants among them $78.6 \%$ were certain sepsis which was significantly different from the other age groups ( $p$ <0.007). There was a significant correlation between positive CRP and certain sepsis in the first, second and third testing steps. It was found that the sensitivity of this test is very high in 24 to 48 hours after the admission.

Conclusion: This study showed that the serumal CRP levels can be used as a quick and sensitive test, to approve or disapprove the certain sepsis especially in the first 24 to 48 hours of neonatal sepsis occurrence.

Keywords: C-reactive Protein, Neonatal sepsis, Blood serum 